\title{
Trabajo y salud mental en tiempos de pandemia
}

\author{
Por: Msc. Jorge Molina \\ Catedrático-Investigador Universidad Centroamericana José Simeón Cañas \\ jmolina@uca.edu.sv
}

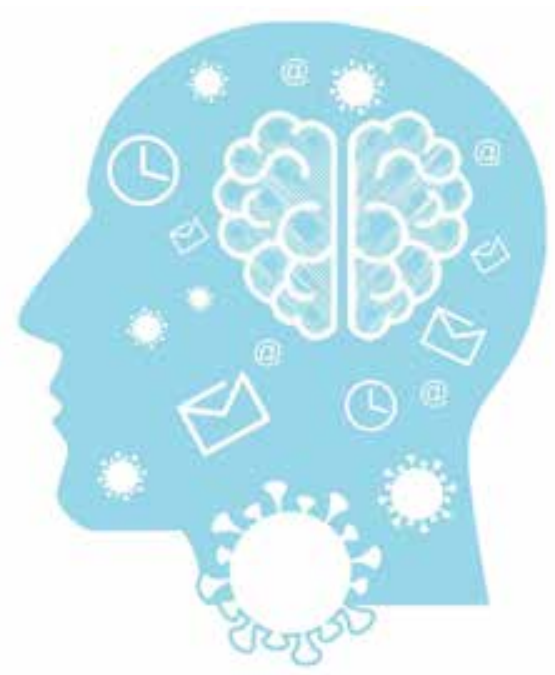

La propagación de la pandemia también está impactando el contexto económico y social. De acuerdo a los datos más recientes de la Organización Internacional del Trabajo (OIT), se estima que un promedio de 1,250 millones de trabajadores (es decir, el $38 \%$ de la población activa mundial) son empleados de los sectores más vulnerables; siendo estos: el comercio al por menor, servicios de alojamiento, comidas e industrias manufactureras. Dichos sectores están recibiendo un golpe duro a su economía, ya que se enfrentan a una caída en sus niveles de producción, y a un mayor riesgo en su fuerza de trabajo -algunos, debido al desplazamiento; y otros, por el cierre (temporal o total) de sus operaciones-. La crisis impacta aún más a países de ingreso bajo y medio, los llamados "países en desarrollo", pues en ellos existe un nivel alto de empleo informal, y un limitado acceso a los servicios de salud, protección social e información.

Paralelo a enfrentar los desafíos que el COVID-19 presenta, existen también los desafíos económicos y sociales, los cuales no deben dejarse a un lado, durante y posterior a la crisis. En este caso, nos enfocamos en la salud, específicamente en la salud mental, la cual, de acuerdo a la Organización Mundial de la Salud (OMS), es un estado de bienestar, en el cual el individuo es consciente de sus propias capacidades, puede afrontar tensiones normales de la vida, trabajar de forma productiva y fructífera, y es capaz de una contribución a la comunidad.

Cuidar de la salud mental implica una serie de actividades que tienen como meta la promoción, protección, el restablecimiento y la rehabilitación de la salud mental. La pobreza, la desigualdad, la discriminación, y la inestabilidad laboral son algunos de los determinantes vinculados al cumplimiento de esta meta.
Algunas compañías alrededor del mundo, incluyendo las de El Salvador, optan por continuar sus labores en la medida de lo posible, a través del trabajo desde el hogar (trabajo remoto). De acuerdo a Víctor Garro y Pedro Palos (The Conversation, 2020), en países como China (con su súper aplicación "WeChat"), Japón, Italia, España, Irlanda, entre otros, los empleados no solo utilizan las plataformas para el trabajo remoto, es decir, para desarrollar capacitaciones, estar en juntas y reuniones; sino también, para informar y estar al tanto acerca del estado de salud de sus colegas. Muchas empresas alrededor del mundo han comprendido la importancia de la salud y, en este caso, de la salud mental de sus trabajadores, en todas las esferas de vida (como la laboral, por ejemplo).

El trabajo remoto (desde casa u otros lugares) no es algo nuevo: muchas empresas, previamente a que sus gobiernos decretaran cuarentena domiciliar y otras medidas, ya comenzaban a desarrollar gran parte de sus actividades en esta modalidad. Inclusive, algunas llevan varios años desarrollando el trabajo remoto, con muy buenos resultados, pues no siempre el trabajo depende de las horas en que una persona se mantiene sentada frente al ordenador adentro de la oficina. Claro, esto requiere recursos, estructura y disciplina por parte de quienes trabajan, y visión y confianza de parte del empleador. Sin embargo, en esta ocasión, el trabajo remoto no ha sido una opción, ni tampoco una estrategia o herramienta de actualización y eficacia; sino una obligación, una imposición de la modalidad; que se agrava frente a otros factores, como el encierro domiciliar, la situación sanitaria propia del COVID-19 $y$, no menos importante: la incertidumbre. 
La incertidumbre no solo emerge de una crisis considerada, según la OIT, como la "más grave desde la Segunda Guerra Mundial", con un aumento rápido en la destrucción del empleo en el mundo-; sino también del mal manejo de la comunicación, de la desinformación, de la promoción del miedo y el terror sobre la enfermedad, del uso o abuso de la fuerza, y del atropello a los derechos humanos. Este panorama puede vincularse a daños en la salud mental de las y los trabajadores: respuestas negativas frente al estrés, angustia, ansiedad, irritabilidad, hipervigilancia, cuadros depresivos, melancólicos, rechazo, nerviosismo, dificultad de concentración, miedo y resignación son solo algunos de los síntomas asociados. Por lo tanto, es importante reconocer que esta pandemia no solo implica un alto costo en la salud física, o en la economía, sino también en la salud mental.

De acuerdo a The Lancet, en una de sus publicaciones más recientes acerca del impacto psicológico de la cuarentena, una revisión a 3,166 publicaciones considera que los efectos negativos en cuarentenas - porque han existido otras cuarentenas en el siglo XXI- oscilan entre el estrés post-traumático, y los síntomas de confusión y enojo, inclusive, tres años después de finalizadas las medidas de cuarentena. Los ejemplos van desde países como Senegal, Sierra Leona y Liberia (2018), que estuvieron en cuarentena por el ébola; hasta Australia (2013), Canadá (2004) y Taiwán (2004), que también adoptaron medidas por el SARS y H1N1.

Especialistas como Joti Samra y la doctora McEachtern, del grupo de psicólogos en Kelowna, Canadá, plantean la posibilidad de aprender sobre estas experiencias, que, si bien no enfrentaban una pandemia de esta magnitud, sí documentaron el impacto psicológico en sus habitantes.

\section{Adaptación, asimilando un cambio}

Es importante considerar que trabajar en casa, sumado a una cuarentena domiciliar, un estado de emergencia, y un panorama complicado, lleno de incertidumbre y muchas veces con aires desalentadores, puede generar más estrés de lo normal; contrario a la idea que algunos tienen. Trabajar desde casa no siempre es fácil, menos en las condiciones actuales. Nos vemos imposibilitados de socializar y dar continuidad a nuestra vida cotidiana: nuestra libertad está comprometida y no podemos salir. En ciertos casos, invade la monotonía y la angustia provocada por el desconocimiento del mañana. Esto se puede volver agobiante.

Algunos especialistas, inclusive, hablan de vivir una especie de duelo. Esto nos permite comprender que el trabajo no solo es el ordenador o la computadora: el trabajo requiere de otras herramientas que son tan propias del ambiente social al cual estamos acostumbrados que, en algunos casos, estimula la creatividad, y en otros, facilita la catarsis.

Esto nos lleva a afrontar un primer reto de esta modalidad de trabajo: adaptación. Esto es desarrollar una serie de hábitos que faciliten el trabajo en casa.

Ello puede tomar tiempo (hasta un mes, según algunos expertos), pues la dinámica impone contrabalancear entre las demandas y tareas del hogar, y ahora, las del mundo laboral. En consecuencia, no será extraño que en este proceso salgan a la superficie desigualdades de género, por ejemplo. Como muestra tenemos el reto de acoplar un espacio físico para desarrollar nuestras tareas laborales. Puede resultar fácil decirlo, pero no todas las personas cuentan con esto. Lo que para algunos son herramientas, como la conexión a Internet, o la computadora con cámara y micrófono periférico, son para otros un privilegio.

Hay quienes cuidan de adultos mayores, o de personas con enfermedades degenerativas, y claro, quienes tienen un rol de madre o padre, ya sea con responsabilidades compartidas, o solos. 
Todo esto, fácilmente, puede convertirse en una serie de presiones, las cuales no desaparecen cuando inicia la videoconferencia, o cuando se reciben correos fuera del horario laboral. Recordemos que la familia y las personas significativas a nuestro alrededor demandan atención y cuidado, $y$, a su vez, forman vínculos importantes en nuestra vida. Pero ellos también se enfrentan al panorama, solo que desde otro ángulo. Todo esto sin tomar en cuenta que un familiar puede resultar infectado, encontrarse en un "centro de contención" o, inclusive, ser nosotros los pacientes. Nuevamente, la adaptación no es imposible, pero requiere tiempo y, sobre todo, comprensión.

\section{El manejo del tiempo}

Es imposible no considerar la "gestión del tiempo". Esto siempre ha sido un reto, más trabajando desde casa con personas que tienen poca experiencia en trabajo remoto. Sin embargo, sumamos a este reto un desafío extra, ese que mencionamos anteriormente: la incertidumbre, e inclusive podemos llegar a mencionar el miedo, la angustia y la ansiedad.

La revista Forbes plantea dos recomendaciones: una gira entorno a aceptar que las reuniones virtuales han incrementado, y probablemente esta tendencia incremente; la segunda trata sobre prestar atención a los fragmentos de tiempo que se presentan entre actividades. Este tiempo al intermedio puede ser de utilidad, inclusive para un descanso activo. Otra recomendación que gira alrededor de estructurar el trabajo en casa es la creación de un calendario (semanalmente), debido a un panorama que puede tener cambios drásticos por la coyuntura.

Acerca de la primera (reuniones) es importante priorizar. Desplegar acciones con el objetivo de vigilar y controlar no siempre es la forma más efectiva $-y$ mucho menos eficaz- de proceder. Esa enorme cantidad de reuniones y más reuniones no acerca al cumplimiento de metas a nadie: cuidado con la "reunionitis aguda".
Lo mismo pasa con los correos: llenar una bandeja de correos no siempre es signo de productividad. A veces, más parece un síntoma de desesperación. Es importante llegar a estos acuerdos con el mismo equipo de trabajo, para no caer en una serie de "meetings" excesivas e innecesarias, que restan tiempo, productividad, y tampoco abonan a la incertidumbre.

\section{Finalmente, ¿qué hacer?}

Algunas recomendaciones para quienes hoy trabajan desde casa y quieren cuidar de su salud mental en un nivel personal pueden ser: no estar todo el tiempo frente al ordenador/computadora y, como bien lo plantea Rocío Pastor (INCAE Business School), no debemos "infoxicarnos" (derivado de "información" e "intoxicación") o llenarnos de noticias; peor aún si son falsas y solo contribuyen a generar terror o un falso optimismo.

Debemos construir un espacio y tiempo para la relajación, orientado a cuidarnos, y respetarlo de la misma forma en que respetamos el espacio y horario laboral. Podemos, además, revisitar algún proyecto que teníamos en pausa (leer un libro, tocar un instrumento musical); mantener contacto con nuestras familias y personas significativas, evitando el aislamiento; hacer cosas que nos divierten: ver series o películas, pues la risa es una herramienta poderosa, como también lo es la gratitud; llevar un diario de eventos positivos resulta útil, y este es un buen momento para iniciarlo (o retomarlo) esto también puede ayudar a identificar nuestras emociones-; realizar actividad física, y no abonar al sedentarismo, que puede resultar nocivo para la salud física y mental, haciendo una rutina breve de ejercicios diarios en casa; $y$, finalmente, pero no menos importante, mantener una higiene adecuada de sueño. 
Laboralmente, como se mencionó antes, hay que tomar en cuenta las condiciones que tenemos para el trabajo, considerando lo ambiental, lo ergonómico y lo tecnológico. Desarrollar, aparte de los correos, nuestro propio calendario con metas-objetivos. Respetar nuestra intimidad, poner límites entre los espacios personales, familiares y laborales; aquí será importante el diálogo entre el empleador y el trabajador, en caso sea necesario negociar los horarios, siendo realistas con su entorno.

Para cerrar, damos algunas recomendaciones para la empresa; pero antes: ¿recuerda todos los seminarios y lecturas sobre estilos de liderazgo?, ¿aquellos relacionados al trabajo en equipo? Sí, esos donde abundan los tópicos acerca de la importancia de la "mejora constante" y la "actualización"; el estar "innovando permanentemente"; la importancia del relevo generacional $y$, sobre todo, la motivación. Hoy es cuando deben reflejarse, pues toda crisis es también una oportunidad, y esta demanda recursos y creatividad; pero, más aún, es una crisis que puede agravarse si la empresa pierde de vista la responsabilidad en el cuidado de la salud mental de sus trabajadores. Los jefes deben estar pendientes del sentir de las personas que tienen a su cargo y enfocar esfuerzos en escuchar a sus compañeros y compañeras, tanto de forma grupal como individual, pues todos viven una especie de duelo, y lo van asimilando gradualmente.

Aquí saldrá a flote si en realidad, quien lidera, orienta y pone atención en la gestión de aspectos de índole socio-emocional. No será difícil si todo este tiempo atrás dedicó recursos a construir relaciones sanas con quienes trabaja, y si estas fueron cohesionadas y cimentadas en la confianza y la empatía con los empleados, y no solo con grupos selectos. La gestión de procesos debe orientarse al trabajo, y a promover la independencia basada en la confianza; no al despliegue invasivo y las alarmas del control, la vigilancia y el castigo. Este es su momento de mostrar solidaridad, empatía, respeto y coherencia. Si esto no emerge de la propia empresa, de sus jefaturas y mandos medios, entonces, es el momento de evaluar y replantearse si las estrategias adoptadas han sido las mejores, a través de una medición objetiva de la satisfacción de empleados/colaboradores por unidad. Así es posible conocer si, de hecho, se están respetando las normas internacionales del trabajo $y$, si, en realidad, los derechos humanos han sido la base en el diseño de las políticas empresariales; o más bien estuvieron todo este tiempo como un elemento decorativo. 